\title{
Aproximación a las dinámicas del conflicto armado en la ciudad de Barranquilla: entre la marginalidad insurgente y el control paramilitar 1990-2006*
}

\author{
Approach to the Armed Conflict Dynamics in the City of Barranquilla: Between Marginalization and Paramilitary \\ Control, 1990-2006
}

Luis Fernando Trejos Rosero ${ }^{\text {a }}$ Universidad del Norte, Colombia trejosl@uninorte.edu.co

ORCID: http://orcid.org/0000-0003-4988-8576

Franklin Martinez Martinez

Uppsala University, Suecia

ORCID: http://orcid.org/0000-0002-6157-4556

Reynell Badillo Sarmiento

Universidad del Norte, Colombia

ORCID: http://orcid.org/0000-0002-3576-8533
DOI: https://doi.org/10.11144/Javeriana.papo23-2.adca Redalyc: http://www.redalyc.org/articulo.oa?id=77757839003

Fecha de recepción: 06 Febrero 2018

Fecha de aprobación: 29 Mayo 2018 Fecha de publicación: 18 Diciembre 2018

\section{Resumen:}

Durante los últimos años, ha sido común considerar que Barranquilla no ha sido escenario de conflicto armado. Sin embargo, el análisis histórico demuestra lo contrario. En el presente trabajo realizamos una aproximación descriptiva a las dinámicas del conflicto armado en la ciudad entre 1990 y 2006. Observamos que tanto las guerrillas como las estructuras paramilitares hicieron presencia activa en ella, modificando aspectos de su vida social, política, económica e institucional.

Palabras clave: conflicto armado, Barranquilla, guerrillas, estructuras paramilitares.

\section{Abstract:}

In the recent years it has been a commonplace to think that Barranquilla has not been a scenery where the armed conflict occurred. However, the historical analysis shows the opposite. In this work we present a descriptive approach to the armed conflict dynamics in this city between 1990 and 2006. We observed that both the guerrilla groups and the paramilitary structures were actively present in the city and modified some aspect the city social, political, economic and institutional life.

Keywords: armed conflict, Barranquilla, guerrillas, paramilitary structures.

\section{Introducción}

El presente trabajo tiene como objetivo realizar una aproximación descriptiva a las dinámicas del conflicto armado en la ciudad de Barranquilla entre los años 1990 y 2006, por ser el periodo de mayor presencia y actividad guerrillera y paramilitar en la ciudad. Esto, con el fin de contribuir al abordaje académico de los procesos de violencia política y superar la idea instalada en el imaginario colectivo de que la ciudad se mantuvo al margen de las dinámicas regionales y nacionales del conflicto armado, a pesar de que en Barranquilla los grupos armados ilegales operaron activamente por medio del Frente Urbano Kaleb Gómez Padrón (FUKGP) del Ejército de Liberación Nacional (ELN), la Red Urbana José Antequera (RUJA) de las Fuerzas Armadas Revolucionarias de Colombia - Ejército del Pueblo (FARC-EP) y el Frente José Pablo Díaz de las Autodefensas Unidas de Colombia (AUC), que al igual que organizaciones de narcotraficantes han llegado a la ciudad por su dinamismo económico y comercial (fundamental para la captura de rentas y

Notas de autor: 
acceso a bienes y servicios) y también por su privilegiada condición de puerto marítimo y desembocadura del río Magdalena. Precisamente, esta ubicación geográfica ha hecho de Barranquilla un punto estratégico para la exportación de clorhidrato de cocaína y el ingreso de dólares, armas e insumos químicos. Es decir, se debe asumir que la ciudad sí fue escenario de la confrontación armada y, por lo tanto, se hace necesario conocer y analizar esta realidad para formular políticas públicas que prevengan la conformación o establecimiento de estructuras armadas en ella, especialmente en sus periferias.

En este sentido, el trabajo se divide en dos partes. La primera aborda la insurgencia urbana, poniendo énfasis en el Frente Kaleb Gómez Padrón del ELN ${ }^{\mathrm{i}}$, porque en enero del 2018 estuvo vinculado a dos ataques con explosivos a sedes de la Policía Nacional en Barranquilla y el vecino municipio de Soledad y por poder contar con el testimonio de un exmilitante de esta estructura. En la segunda, se analizan las actividades ilegales desarrolladas por el Frente José Pablo Díaz de las AUC.

La técnica de análisis que más se utilizó es la derivada del análisis hermenéutico de documentos y textos, confiando en la capacidad del investigador para analizar y contrastar la validez interna y externa de los documentos utilizados. La investigación de los documentos se base en testimonios humanos, en especial los escritos. En este caso, la fiabilidad se da con la verificación de la autenticidad del documento, la competencia de quien lo produce, sus conocimientos sobre el tema, su ideología, la pertenencia a una organización, movimiento o partido político y el fin que busca el documento (Ragin, 2007). En el mismo sentido, Pardinas (1989), al referirse a la observación documental, afirma que al realizar el análisis tradicional se debe tener muy en cuenta la autenticidad textual, histórica y literaria del documento sometido a análisis. El enfoque del trabajo es cualitativo, bibliográfico y descriptivo.

\section{Contexto geográfico}

Barranquilla es una de las ciudades más pequeñas del país en cuanto a superficie territorial ${ }^{\text {ii }}$, empero, es la más poblada del Caribe colombiano y la cuarta a escala nacional. Esto y su grado de desarrollo hacen que sea "considerada por muchos la capital de la región Caribe" (Pérez, 2014, p. 4). Según el citado autor, la participación de Barranquilla en el PIB nacional es en promedio de 3,7\% durante la primera mitad de la década del 2010, y en el 2016 la Cámara de Comercio de Barranquilla expresó que la participación del departamento del Atlántico llegó a ser del 4,2\% a escala nacional y 28,1\% a escala regional.

Esta significante posición económica no es fortuita ni novedosa. A pesar de que Barranquilla nació en los albores del siglo XIX, mucho después de que grandes ciudades como Bogotá (1539), Cali (1536) o Medellín (1616) fueron fundadas, su acomodada posición geoestratégica en la desembocadura del río Magdalena y su salida al mar le permitieron conectar el interior del país con los más importantes mercados internacionales. La importancia que adquirió fue tal que en sus mejores años llegó a transportar el 60\% del comercio exterior nacional (Bonilla, 2010). La ciudad se vio positivamente afectada por la bonanza cafetera, ya que los productores en el centro del país necesitaban exportar el grano a Europa y los Estados Unidos, y la costa Caribe era un paso obligado (Villalón, 2003). No obstante, el aumento constante del transporte a través del océano Pacífico debido, entre otras razones, a la apertura del canal de Panamá y la modernización del puerto de Buenaventura durante la década de 1920, resintió el volumen de mercancía que se dirigía hacia los puertos del Caribe (Meisel, 1993). Para Villalón (2003), los factores favorables para Barranquilla se diluyeron durante la década de 1940, coincidiendo con un "desvío del comercio internacional hacia el puerto de Buenaventura" (p. 117) y la decreciente importancia que se le daba a la navegación fluvial por el río Magdalena.

En esta línea, es importante señalar que para la insurgencia la ciudad resulta estratégica por varios motivos, entre ellos que la ciudad y el departamento del Atlántico funcionan como bisagras entre dos sistemas montañosos que albergaron el grueso de las estructuras guerrilleras rurales que operaron en la región Caribe: la Sierra Nevada de Santa Marta (Cesar, Guajira y Magdalena) y los Montes de María (Bolívar y 
Sucre). Además, su dinamismo comercial la convierte en una fuente de acceso a bienes y servicios, con una gran cantidad de organizaciones sociales (influenciables y cooptables por actores armados) presentes en su territorio.

\section{La insurgencia armada en la ciudad de Barranquilla. Tres momentos de estudio}

El primer momento puede denominarse de antecedentes u origenes, en la década de los ochenta. En este periodo, según el Observatorio del Programa Presidencial de Derechos Humanos y DIH (2005), hacían presencia en la ciudad el Ejército de Liberación Nacional (ELN), el Ejército Popular de Liberación (EPL) iii y el Movimiento 19 de abril (M-19), desarrollando acciones armadas con fines políticos, militares y económicos.

En este sentido se destacan, entre otras acciones armadas, la toma del barrio El Pueblito por parte del Frente Urbano Bernardo Ferreira Grandet del EPL, el 4 de marzo de 1988, día en el que entre las 7:30 y las 9:00 p. m., aproximadamente, ochenta guerrilleros encapuchados irrumpieron en el barrio, lanzaron proclamas contra la Fuerza Pública y buscaron sin éxito a los directivos de la Junta de Acción Comunal, a quienes acusaban de corrupción (“Toma del ELN en Las Malvinas", 1988). El 30 de mayo del mismo año, miembros del ELN se tomaron la sede de la Acción Cívica del barrio Las Malvinas (“Toma del ELN en Las Malvinas”, 1988).

El segundo momento, que va de 1991 al año 2000, puede denominarse como el de "desarrollo y decadencia". En este periodo se desmovilizan el M-19 y el EPL y se consolidan las FARC-EP y el ELN por medio del establecimiento de estructuras urbanas permanentes que, según Arias (2008), en 1992 realizaron ataques contra estaciones de policía de los barrios El Silencio y El Hipódromo, entidades bancarias, la sede de Fedegan, buses de transporte público y los instrumentos de navegación del aeropuerto Ernesto Cortissoz.

En la misma línea, realizaron varios secuestros extorsivos, destacándose el de la ciénaga del Torno por parte del ELN, el 6 de junio de 1999, en el que fueron privadas de la libertad nueve personas, entre quienes se encontraban el entonces concejal de Barranquilla Orlando Rodríguez y su hijo Boris Rodríguez ("ELN liberó a secuestrado de la ciénaga El Torno", 2000).

Según el excomandante paramilitar Rodrigo Tovar Pupo, alias Jorge 40, este secuestro masivo aceleró la entrada de las Autodefensas Unidas de Colombia (AUC) al departamento del Atlántico y provocó la masacre de Nueva Venecia, perpetrada el 22 de noviembre del año 2000 y en la que fueron asesinados 39 pescadores (véase "La masacre de Nueva Venecia se originó en Pivijay", 2008; "La barbarie”, 2001). Para entender el funcionamiento del ELN en la ciudad de Barranquilla durante este periodo, se cuenta con el testimonio de

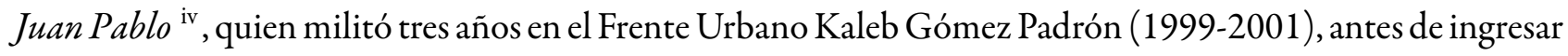
a una estructura rural ${ }^{\mathrm{v}}$.

Sobre su ingreso al ELN y la estructura orgánica del frente, manifiesta lo siguiente:

Me incorporé en el año 1999, siendo estudiante de la Universidad del Atlántico. Ahí, hacía parte de un grupo estudiantil y ese año me invitaron a una reunión en la que me hicieron la propuesta, luego de eso vino una entrevista con dos miembros del ELN y ahí se concreta el ingreso, se me describe la organización, el frente y cuales serían mis tareas, que en un principio se limitaban a la Universidad. Teniendo como prioridad no tanto el reclutamiento, sino influenciar y crear otras organizaciones estudiantiles, que fueran afines a la organización armada. Para 1999 el frente contaba con una dirección, que en ese momento estaba conformada por cuatro miembros. Cada miembro era responsable de un área específica (político, militar, finanzas y organización), y cada uno atendía a su vez a Grupos de Estudio y Trabajo (GET) o colectivos (sindicales, estudiantiles, barriales)\}, de máximo tres integrantes y en cada uno debía haber por lo menos un premilitante. Ningún colectivo o GET tenía contacto con otro, esto con el fin de preservar el trabajo.

¿Qué hacia el FUKGP en Barranquilla? 
En general el grueso del trabajo era político-organizativo y en menor medida de apoyo logístico a los frentes rurales, ya que militarmente prácticamente no se hacía nada. El objetivo era la construcción y consolidación de una o varias Bases Revolucionarias de Masas (BRM), que en la práctica consistía en controlar política y militarmente un barrio o sector de la ciudad para desde ahí impulsar el proceso insurreccional.

\section{¿Cuál era su función en el FUKGP?}

Al principio mi trabajo se concentró en la Universidad del Atlántico, tenía que montar una organización estudiantil amplia, en concreto una Organización Política de Masas (OPM), esta es una figura organizativa copiada de los Comités Internacionales de Solidaridad con el Pueblo de El Salvador (CISPES), que eran organizaciones civiles que apoyaban a la guerrillera salvadoreña Farabundo Martí para la Liberación Nacional, estos comités, en la práctica funcionaban como las Organizaciones Políticas de los Obreros, planteadas por Lenin en su libro ¿Qué hacer vi ?, los comités (Organización Política de Masas), son una instancia intermedia que articula y cualifica entre el ELN (vanguardia armada) y las bases (masas). Aquellos individuos de las bases que se destaquen por su activismo y compromiso con la causa elena pasan a la vanguardia (organización armada), los que no, siguen en la OPM. Posteriormente asciendo a militante y asumo otros espacios sociales y barriales, que van adquiriendo cierto dinamismo hasta la llegada de las AUC en el año 2000, ahí todo se vino abajo, tanto en lo estudiantil como en lo social. No hubo forma de resistir la embestida paramilitar.

¿Por qué gana el paramilitarismo la disputa por Barranquilla?

Creo que por cuatro razones concretas, la primera se relaciona con la marcada debilidad de los frentes urbanos del ELN en el Caribe $^{\text {vii }}$, que en la práctica funcionaban más como extensiones logísticas de los frentes rurales. La segunda se relaciona con que los frentes urbanos no lograron desarrollar ningún tipo de operatividad armada. La tercera, era la dependencia estructural en términos militares y económicos de la dirección del Frente de Guerra Norte que operaba en zonas rurales. Y cuando el paramilitarismo empieza a controlar las ciudades capitales, las cabeceras municipales y las entradas a la Sierra Nevada de Santa Marta, los Montes de María y la Serranía del Perijá, se produjo la parálisis de los frentes urbanos, ya que perdieron espacios sociales y políticos al quedarse sin recursos. Por último, debe tenerse en cuenta que el paramilitarismo operó con libertad en la ciudad, realmente nunca hubo una acción represiva continuada en su contra.

Es precisamente en este contexto en el que se da la tercera y última etapa, "la marginación", que va del año 2001 hasta el 2006. En esta etapa se consolida el paramilitarismo como actor ilegal hegemónico en la ciudad y la actividad insurgente desaparece casi en su totalidad. Arias (2008) reporta que entre el 2001 y el 2004 en la ciudad se produjeron múltiples capturas de miembros, no solo de la RUJA, sino también de los frentes 19, 35 y 37. En este marco, el 16 de diciembre del 2003 las FARC, con el fin de presionar el pago de extorsiones, desataron una escalada terrorista en tres almacenes de cadena, ubicados en la 93, en la calle Murillo con 27 y en la calle 53 con 46, lo que dejó un trágico saldo de un muerto y 65 heridos, luego de que se detonaran cargas explosivas de manera simultánea.

\section{Antecedentes del crimen organizado en la ciudad de Barranquilla: la bonanza marimbera y el narcotráfico}

A pesar de la pérdida de dinamismo de la capital atlanticense a finales de la primera mitad del siglo XX, durante los años setenta, la bonanza marimbera, que tuvo como principales protagonistas en la región Caribe a la Sierra Nevada de Santa Marta — principalmente por su área de sembrado_y La Guajira —como epicentro de acopio y exportación de marihuana-, permitió una "estructuración y permanencia en toda la región de una red de agentes legales e ilegales - sicarios, testaferros, lavadores de activos, políticos, jueces, policías y militares" (Trejos, 2017, p. 1) a la que Barranquilla no fue inmune. La ciudad fue vista por los marimberos como refugio seguro, dado el perfil bajo que podían ostentar allí y la sensación de encontrarse en una ciudad con renombrado impulso industrial y comercial (Ardila, Acevedo y Martínez, 2012), aunque, como lo expresa Villalón (2003), este relato de éxito podría haberse tratado de un mito ocasionado por el frustrante momento económico de Barranquilla. 
En dicha época, la capital atlanticense fue considerada "el mayor epicentro urbano del boom" marimbero (Brito, 2008, p. 17), y, además de pequeños patrones de consumo que estimularon el crecimiento del sector de la construcción, la economía marimbera incidió sobre los niveles de violencia de las ciudades en las que sus protagonistas se asentaron. En Barranquilla, tal como lo explica Trejos (2013), una de las evidencias del paso de la bonanza marimbera fue la incubación de "toda una tradición socio-cultural en torno al narcotráfico" ( $p$. 122) hacia finales de los setenta e inicios de los ochenta debido a la proliferación y profesionalización del sicariato como elemento reiterativo a la hora de resolver conflictos y cobrar cuentas.

La época de la bonanza marimbera es considerada la primera etapa de la articulación del narcotráfico en Barranquilla, dado que, además de la mudanza de los marimberos, existe evidencia de que la ciudad se convirtió en uno de los principales centros comercializadores de la marihuana (Observatorio del Programa Presidencial de Derechos Humanos y DIH, 2005). Asimismo, tal como lo explica González-Plazas (2008), si bien por mucho tiempo se expandió la hipótesis de que puertos como los de Barranquilla y Cartagena estaban relacionados con las dinámicas de contrabando y narcotráfico que provenían de Maicao y parte de La Guajira, fue hasta el 2002 en la Operación Conquista ${ }^{\text {viii }}$ cuando al fin hubo certeza de que la influencia que había ejercido la bonanza marimbera sobre algunas ciudades de la región se encadenaba con su condición de puerto marítimo y no se limitaba a un simple fenómeno migratorio.

\section{La consolidación del narcotráfico en Barranquilla}

Como es posible inferir, la posición geográfica de Barranquilla y su condición doble de puerto fluvial y marítimo no solo suscita la atención de los actores comerciales legales, sino que otorga ventajas también para las actividades económicas ilegales (Observatorio del Programa Presidencial de Derechos Humanos y DIH, 2012). Concretamente, el narcotráfico empezó a hacer mella en la ciudad a partir de los años ochenta con la conformación del llamado Cartel de la Costa, que tuvo como centro de operaciones a Barranquilla y Santa Marta. Aun así, cabe aclarar que ni Barranquilla ni la región Caribe en general han sido sedes de carteles poderosos, ni ejes gravitacionales del narcotráfico en el país, sino que han servido, por su privilegiada posición costera, como puntos estratégicos en aras de exportar drogas e ingresar armas e insumos químicos que mantengan a flote la actividad criminal (Trejos, 2017).

El Cartel de la Costa, junto a estructuras como el Cartel de Bogotá y el Cartel de los Llanos, fueron clasificados por Robert y Rodier (2013) como pequeños carteles independientes, en relación con organizaciones más poderosas como los carteles de Medellín y Cali, que dominaron el mercado del narcotráfico en el país. En Barranquilla, el líder de este cartel fue Alberto Orlández Gamboa, alias el Caracol, quien dirigía el envío de cargamentos hacia Estados Unidos mediante un proceso descrito por los organismos de seguridad:

[...] El procedimiento del cartel de la Costa para llevar la marihuana a Estados Unidos se inicia con la gran cosecha que ha dado este año la Sierra Nevada de Santa Marta. De allí es bajado el cargamento en asno, para ello se le paga a la cuadrilla 19 de las FARC un impuesto por cada carga que baja, y transportado por tierra hasta fincas del Atlántico, donde la hierba es empacada en cartones de cigarrillos y enviada a las caletas de la playa, donde es recogida por pequeñas lanchas y llevada a los barcos en alta mar. ("Golpe al Cartel de la Costa en el Atlántico", 1993)

Orlández Gamboa era un antiguo miembro del Cartel de Cali que, luego de su desaparición, se estableció en Barranquilla e hizo del Cartel de la Costa "una de las bandas de narcotraficantes más poderosas del país" ("Desmantelan un cartel del narcotráfico", 1998).

En este cartel también resaltó el llamado clan Nasser Arana, liderado por Julio César Nasser David, alias el Turco, y su exesposa Sheila Arana. Ellos, considerados los narcotraficantes más importantes del Cartel de la Costa, empezaron sus actividades ilegales en 1974, en medio de la bonanza marimbera, como contrabandistas de licores y cigarrillos, y con el tiempo transitaron hacia el tráfico de cocaína y marihuana 
("Efecto dominó", 1999). Los Nasser Arana lograron introducir a Estados Unidos más de 25.000 kilos de cocaína y 1.400 .000 kilos de marihuana entre 1976 y 1999 , cuando todos los miembros de la familia fueron capturados (Rodríguez, 2016). Además de su involucramiento en el narcotráfico, esta familia fue reconocida en la ciudad por hacerse con un gran número de propiedades emblemáticas para la ciudad, entre ellas el hotel El Prado, el edificio de Miss Universo y el centro comercial Villa Country ("Extinción de dominio arrancó en Barranquilla", 1997).

El Cartel de la Costa se desarticuló a finales de los noventa, tras las capturas de Orlández Gamboa en 1998 y el desmantelamiento del clan Nasser Arana un año después. Sin embargo, ello no significó la desaparición del narcotráfico en el Atlántico. Durante los años previos a la total desaparición del cartel, algunos grupos criminales del norte del Valle participaron en el asesinato de varios colaboradores de Caracol y de alias Tito, hijo de Julio César Nasser David, con la intención de dominar el tráfico de estupefacientes en el departamento y quedarse con las redes de exportación de cocaína del Cartel de la Costa (Observatorio del Programa Presidencial de Derechos Humanos y DIH, 2012).

El grupo más importante de los provenientes del norte del Valle era el conformado por los hermanos Víctor y Miguel Ángel Mejía Múnera, quienes desde mediados de la década de 1990 se habían adentrado en la región con el objetivo de dominar las salidas de cocaína hacia México a través de los puertos de Barranquilla y Cartagena, considerados sus más importantes puntos de embarque y acopio en la costa norte de Colombia (Observatorio del Programa Presidencial de Derechos humanos y DIH, 2005).

Víctor fue reconocido en la ciudad porque desató una ola de asesinatos entre jóvenes de la clase alta barranquillera, y colaboró en la fundación del combo Los Magníficos, como fue conocido un grupo de sicarios que trabajaba para los mellizos Mejía Múnera y que aún después de que los hermanos dejaran la ciudad, seguía arreglando cuentas bajo la orden, sobre todo, de Víctor. La importancia de los Mejía Múnera en las redes del narcotráfico en Barranquilla no fue poca, teniendo en cuenta que contaban con clientes como los traficantes mexicanos Amado Carrillo y Joaquín, alias el Chapo, Guzmán ix (“Celos enfermizos del 'Mellizo”, 2014).

Los Mellizos, como también fueron conocidos, no eran extraños en el mundo del narcotráfico. A comienzos de los noventa trabajaron para el Cartel de Cali cuidando los cargamentos de coca que el grupo narcotraficante enviaba desde Buenaventura hacia el golfo de México. Los hermanos

[...] viajaban como polizones en los barcos cuidando que a la "carga" no le fuera a pasar nada o de lo contrario respondían con sus vidas. La paga por ese trabajo les reportaba cinco millones de pesos por viaje y cada entrega demoraba poco más de un mes. (“Los narcogemelos", 2001)

Las capturas de los principales líderes de los grandes carteles del país por parte de las autoridades y el consecuente debilitamiento de estas estructuras de narcotráfico originaron una guerra entre mandos medios que, si bien no pretendían reemplazar a sus otrora jefes, esperaban sí cooptar los emporios regionales y dominar las rutas de narcotráfico a fin de mantener el tráfico de cocaína ("Los narcogemelos", 2001). Fue el caso de los Mejía Múnera, quienes, utilizando la experiencia adquirida en el Cartel de Cali, en 1994 conformaron un grupo delincuencial para el tráfico de estupefacientes en la costa atlántica, con el visto bueno del entonces líder del llamado Cartel de la Costa, Alberto Orlández Gamboa ("Perfil de Miguel Ángel Mejía Múnera", 2008).

Como ya ha sido dicho, los mellizos Mejía Múnera lograron, a través de la creación de nuevas rutas de narcotráfico en la costa norte de Colombia, establecer con éxito esta empresa criminal. A pesar de los golpes asestados por las autoridades durante operaciones como Transatlántico, Orinoco y Horizonte fase 2 x , lograron sobrevivir en el Atlántico hasta comienzos del milenio cuando, acechados por la incursión de las AUC y movidos por los beneficios de las penas alternativas establecidas en el acuerdo pactado entre el gobierno de Álvaro Uribe Vélez y la organización paramilitar, ofrecieron a Vicente Castaño dos millones de dólares a cambio de que les otorgara el mando del Bloque Vencedores de Arauca, donde Miguel fingió su desmovilización como máximo líder de la organización contrainsurgente a pesar de que solamente visitó 
la región en tres ocasiones y mantuvo su perfil como narcotraficante ("Cupo del 'Mellizo' en proceso con las AUC valió US\$ 2 millones”, 2017; “Los mellizos’, Miguel Ángel Mejía Múnera y Víctor Manuel Mejía Múnera”, 2008).

Así, los Mejía Múnera lograron quedarse con las rutas del desmantelado Cartel de la Costa hasta la llegada del frente JPD, cuando se vieron obligados a cederlas a estos últimos a través de negociaciones con Rodrigo Tovar Pupo (Observatorio del Programa Presidencial de Derechos Humanos y DIH, 2005).

\section{El terror paramilitar: la llegada del frente José Pablo Díaz}

Las Autodefensas Campesinas de Córdoba y Urabá ${ }^{x i}$ incursionaron en la costa norte colombiana entre 1980 y 1995, con el pretexto de combatir los frentes 6 de Diciembre y José Manuel Quiroz del ELN, y las células de la otrora guerrilla de las FARC que operaban sobre todo en la serranía del Perijá y sus municipios circunvecinos. Empero, en el departamento del Atlántico no harían presencia sino hasta finales de los años noventa, cuando se creó la estructura denominada Bloque Norte, perteneciente a las AUC, al mando de Tovar Pupo (Tribunal Superior del Distrito Judicial de Bogotá, Sala de Justicia y Paz, 2011).

De los catorce frentes con los que contaba el Bloque Norte, dos hicieron presencia en el Atlántico: el ya mencionado Frente JPD y el Frente Tomás Guillén. No obstante, este último operaba principalmente en el Magdalena, en los municipios de Pivijay, Salamina, Ciénaga, Remolino, Cerro de San Antonio, Concordia, El Piñón, Pedraza y Plato, por lo que también fue conocido como Frente Pivijay. La cercanía de estos municipios con Barranquilla y el interés de beneficiarse de la entrada y salida al mar que representaba la capital del Atlántico los llevó a, de manera ocasional, realizar acciones en este departamento ("Audiencia concentrada del 'Frente Pivijay'”, 2015; Montes, L. Marti\#nez, N. Marti\#nez, Rena\#n y Silva, 2014; Valencia, 2009). De esta forma, podría afirmarse que el frente JPD fue el único que se estableció en el departamento del Atlántico y que mantuvo acciones permanentes hasta concretado el proceso de desmovilización con las AUC ${ }^{\text {xii }}$.

A pesar de que Tovar Pupo expresó que el frente JPD nació en razón de la necesidad de "neutralizar el accionar de los frentes Diecinueve, Francisco Javier Castaño y José Antequera de las FARC, y el frente Pabón del ELN" (Tribunal Superior del Distrito Judicial de Bogotá, Sala de Justicia y Paz, 2011, p. 8), en realidad, como bien lo explican Arias (2008) y Trejos y Posada (2014), en la ciudad el accionar guerrillero era casi inexistente cuando el grupo paramilitar incursionó, por lo que las motivaciones de la organización paramilitar estuvieron más asociadas con el control del narcotráfico y el crimen organizado (Trejos, 2013).

Sin embargo, la primera acción significativa del Grupo Atlántico fue una respuesta ante el secuestro de nueve personas barranquilleras en la ciénaga de El Torno por parte del ELN. Las autodefensas reaccionaron asesinando a cerca de sesenta pescadores, "como un acto de retaliación por el secuestro" (Arias, 2008, p. 4). Según alias Jorge 40, Carlos Castaño tenía mucho interés en realizar esa operación para penetrar en el departamento del Atlántico (Arias, 2008). Lo anterior coincide con las declaraciones del mismo Tovar Pupo en la versión libre ante la fiscal de Justicia y Paz recogidas por Pedraza y Olaya (2011). En estas el líder paramilitar afirma que "meterse en el departamento del Atlántico, era una obsesión de la casa Castaño” (Pedraza y Olaya, 2011, p. 191).

\section{El Grupo Atlántico y la incursión de las AUC}

A pesar de que el Cartel de la Costa se desarticuló por completo y la predominancia de los mellizos Mejía Múnera en Barranquilla se difuminó con la incursión del paramilitarismo, el narcotráfico no dejó de ser un elemento fundamental para entender la violencia en la ciudad. El río Magdalena seguía teniendo un carácter estratégico para sacar droga hacia el mar y esto sería aprovechado por el Bloque Norte de las AUC. Por lo 
anterior, la llegada del frente JPD exacerbó los niveles de homicidios, sobre todo en entornos cercanos a los terminales marítimos como los barrios Rebolo, La Chinita el Ferry y la Luz (Observatorio del Programa Presidencial de Derechos Humanos y DIH, 2012).

La figura 1 permite observar que la tasa de asesinatos en la ciudad aumentó aproximadamente en un 52\% entre el 2000 y el 2003, y que desde el 2004 registra una disminución sostenida. Como podremos apreciar más adelante, esta disminución no significó una debilidad del frente JPD, sino que, por el contrario, obedece a su consolidación en la ciudad. Arias (2008) explica que

El incremento de la violencia en el 2000, en la capital barranquillera se debe a la entrada del Bloque Norte con el fin de apropiarse de los mercados ilegales, así como otros que siempre están en la frontera de la legalidad y la ilegalidad como la conformación de empresas de seguridad privada y los grupos de prestamistas (paga-diario) entre otros. (p. 5)

Además, es necesario mencionar que, en el momento del arribo paramilitar, la banda de Dino Meza era la que había logrado consolidarse en las calles de Barranquilla como la organización que controlaba la criminalidad y la extorsión. Según información recogida en El Tiempo ("Así fue cómo los paramilitares se tomaron el departamento del Atlántico”, 2007), esta banda recogía más de diez millones de pesos diarios a través de sus servicios de seguridad y extorsión (los mismos que en el futuro ofrecerían las AUC). Así, los paramilitares debieron deshacerse de Dino Meza ${ }^{\text {xiii }}$ antes de expandir su influencia en el Atlántico.

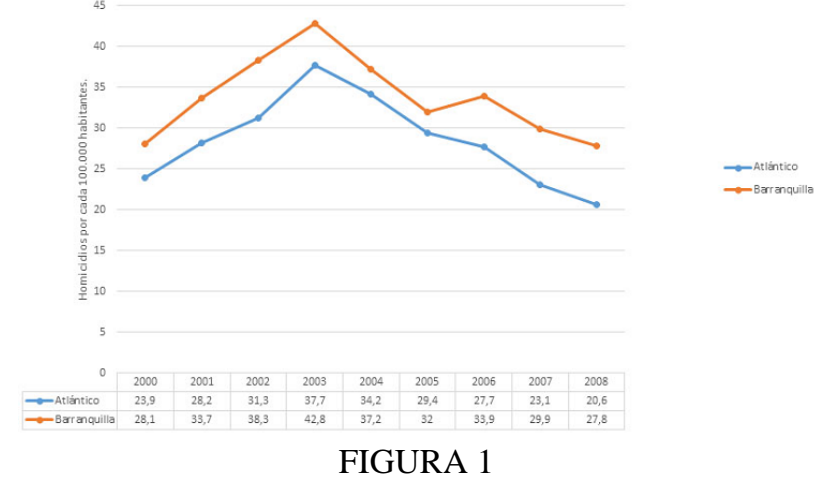

Tasa de homicidios en Barranquilla comparada con el departamento del Atlántico (2000-2008)

Fuente: elaboración propia a partir de los datos recogidos por el Observatorio del Programa Presidencial de Derechos Humanos y DIH (2012)

A las AUC, su presencia en el Atlántico les garantizaba ventajas geoestratégicas debido a que el departamento es un corredor de movilidad que conecta el Atlántico con el Magdalena hasta la Sierra Nevada de Santa Marta y tiene acceso a la troncal del Caribe (que conecta a Santa Marta y La Guajira) y la carretera Oriental (que facilita el acceso a los Montes de María y el sur de Bolívar) (Observatorio del Programa Presidencial de Derechos Humanos y DIH, 2012).

Este interés por el Atlántico puede entenderse mejor a la luz de la presencia del grupo criminal en el Caribe colombiano a comienzos de la década del 2000: autodefensas como las lideradas por Chepe Barrera, Hernán Giraldo y Adán Rojas se habían expandido por los departamentos de Magdalena y Bolívar antes de la llegada de las AUC. En 1997, con la conformación del Bloque Norte, estos grupos de autodefensas empezaron a ser sometidos o se fusionaron con el naciente emporio paramilitar y conformaron un poder criminal sólido en la costa norte del país. Así, aunque las autodefensas no hayan nacido en Barranquilla, sí tenían arraigo en las zonas circunvecinas, lo que despertó un fuerte interés por ingresar a la capital atlanticense y establecer un corredor de movilidad que facilitara el acceso a sus zonas de influencia (Observatorio del Programa Presidencial de Derechos Humanos y DIH, 2005). En ese escenario, los paramilitares comenzaron su misión de internarse en el Atlántico por el pueblo de Palermo, limítrofe con el puerto de Barranquilla, y, antes de alcanzar la capital barranquillera, arribaron a Soledad y a municipios más pequeños del departamento (“Don Antonio, el hombre detrás del computador de Jorge 40”, 2009).

A partir del 2000, en Barranquilla no solo hubo un aumento pronunciado de los asesinatos, sino que el desplazamiento forzado "pasó de 966 personas en 1999 a 6.297 en el 2000 y a 10.778 personas en 
el 2001" (Trejos y Posada, 2014, p. 47). La violencia contra sindicalistas, profesores y miembros de la Universidad del Atlántico aumentó significativamente - alrededor de 35 sindicalistas y 12 docentes fueron asesinados entre el 2000 y el 2004, y en el mismo periodo 20 profesores y alumnos de la universidad departamental fueron desplazados- (Observatorio del Programa Presidencial de Derechos Humanos y DIH, 2005). El Grupo Atlántico empezó a cobrar cuotas a comerciantes de la ciudad a cambio de protegerlos de asesinatos y atracos que miembros del mismo grupo perpetraban ("El silencio, sombra protectora de los 'paras' en Barranquilla”, 2007). Además, protagonizó las mal llamadas "limpiezas sociales”, a través de empresas de seguridad, e inició el proceso de apropiación de los recursos del chance y los llamados "paga diarios" (Observatorio del Programa Presidencial de Derechos Humanos y DIH, 2012).

Finalmente, alias Pablo - como era conocido José Pablo Díaz, comandante del Grupo Atlántico- fue asesinado en la carretera troncal del Caribe en medio de una emboscada del Frente XIX de las FARC, y el grupo fue rebautizado en honor a su nombre. En adelante, Édgar Ignacio Fierro, alias Don Antonio, fue puesto al mando del FJPD, y se desató una campaña de terror sin precedentes en Barranquilla y varios municipios del departamento.

\section{Funcionamiento de estructuras paramilitares en Barranquilla}

Las investigaciones sobre las estructuras paramilitares en la ciudad de Barranquilla, y en general en el departamento del Atlántico, son escasas. Resalta el trabajo de Trejos y Posada (2014) en la cual se describe la historia del FJPD, fundado en el año 1999 hasta su desmovilización en el año 2006. Del mismo modo, los trabajos de Romero y Ávila (2011) y de López y Ávila (2010) dan cuenta de las diferentes manifestaciones del fenómeno paramilitar en el departamento del Atlántico, enfocándose en los casos del Hospital Materno Infantil de Soledad, así como de las alcaldías de los municipios de Santo Tomás, Malambo y aun Barranquilla.

Sin embargo, la información correspondiente a la ciudad de Barranquilla y el funcionamiento de las estructuras paramilitares se ha concentrado más en reportes de prensa, entrevistas a vinculados a procesos judiciales y menciones en medios locales, lo cual ha hecho que la información esté dispersa y no se logre establecer patrones generales de funcionamiento de la estructura paramilitar que hizo presencia en la ciudad.

En las próximas páginas se hará una aproximación a cómo funcionaba la mencionada estructura, quiénes hacían parte de ella, cómo se financiaba, y las diferentes instituciones formales e informales en las cuales el paramilitarismo hizo presencia y utilizó a su favor.

\section{Organización del frente José Pablo Díaz}

El frente JPD estuvo dirigido, entre el año 2003 y el 2006, por Édgar Ignacio Fierro Flores, alias Don Antonio, o Antonio, como él mismo se llamaba. En este periodo, Antonio dirigió las acciones criminales de este frente, el cual le respondía directamente a Jorge 40, comandante del Bloque Norte de las AUC y quien dirigió la operación criminal de esta organización en el Caribe colombiano.

De acuerdo con la sentencia de primera instancia contra Édgar Ignacio Fierro Flores y Andrés Mauricio Torres León, de la Sala de Justicia y Paz del Tribunal Superior del Distrito Judicial de Bogotá (2011), el FJPD estaba dividido en diversas comisiones, cada una de las cuales dirigía una parte del territorio del departamento del Atlántico, así:

\footnotetext{
Comisión Metropolitana: encargada del municipio de Soledad, el mercado público de Barranquilla y el resto del área urbana. Comisión Centro: encargada de los municipios de Baranoa, Galapa, Polonuevo y Usiacurí, con sus corregimientos y veredas.

Comisión Oriental Norte: a su cargo los municipios de Malambo, Sabanagrande, Santo Tomás, Palmar de Varela, Ponedera, Candelaria, Santa Lucía y Suán.
} 
Cordialidad: actuaba en los municipios de Sabanalarga, Luruaco, Repelón y Manatí, con sus corregimientos y veredas. Magdalena: encargada del municipio de Sitio Nuevo, con sus corregimientos y veredas.

Vía Al Mar: conformada por Puerto Colombia, Juan de Acosta, Tubará y Piojó, con sus corregimientos y veredas. Comandada por Salomón, utilizada principalmente para la exportación de cocaína.

Financiera: liderada por alias Richard, Iván o 28.

Gasolina: comandada por alias Gon.

Política: comandada por Carlos Mario García Ávila, alias Gonzalo o el Médico.

Inteligencia: comandada por alias Cucho.

Es necesario distinguir dos elementos principales de organización del frente. Si bien todas las comisiones hacían parte de este, las responsabilidades y lealtades hacia comandantes variaban. Así, por ejemplo, las comisiones Metropolitana, Centro, Oriental Norte, Cordialidad, Magdalena, Financiera, Gasolina e Inteligencia dependían directamente de Antonio - y en parte también dependía de este la Comisión Política -, pero la Comisión Vía Al Mar y la Política, así como el mismo Antonio, dependían directamente de Jorge 40 ("Don Antonio 1 parte", 2009). Esto no solo demuestra que este último estaba directamente relacionado con la exportación y las rutas de narcotráfico en Barranquilla, sino que además soporta la hipótesis explicativa de que las AUC eran una federación de organizaciones criminales (Salinas y Zarama, 2012).

No es de extrañar entonces que el alcance y la preponderancia de los comandantes de las comisiones que respondían directamente a Jorge 40 fueran mayores que los de los comandantes de comisiones bajo el mando de Antonio. En este sentido, por ejemplo, Carlos Mario García Ávila, Gonzalo o el Médico, gozaba de influencia a escala nacional, al punto de convertirse en el encargado de organizar la estrategia y el proyecto político paramilitar en el Caribe colombiano. Tal influencia demostraría que el Bloque Norte y el FJPD no solo buscaron manejar las rutas del narcotráfico, sino que soportaron financiera y electoralmente a políticos de la ciudad y el Caribe, a cambio de apoyo legislativo en el Congreso de la República. Ejemplo de ello, la promulgación de la Ley 975 de 2005, o Ley de Justicia y Paz, en la cual Gonzalo asegura haber tenido una fuerte influencia ("La confesión de alias 'Gonzalo”, 2013; "Yo le hice 'lobby' a la Ley de justicia y paz”, 2006).

Adicionalmente, la mencionada estructura paramilitar le permitió al frente mantener una organización, finanzas, control social, militar y económico eficiente sobre todo el departamento del Atlántico y parte del departamento de Magdalena. Como se ha dicho, la presencia de estructuras paramilitares en Barranquilla no obedeció a objetivos contrainsurgentes, sino a sus vínculos con el narcotráfico y el crimen organizado. En este sentido, la organización del FJPD se articuló de forma tal que pudiera controlar el paso de cargamentos de cocaína por el departamento del Atlántico, manejando así la protección, el transporte, el acopio y el control de los puntos de exportación de la cocaína — los cuales les generaban, anualmente, alrededor de dos millones de dólares- (Trejos y Posada, 2014).

De acuerdo con la Sala de Justicia y Paz del Tribunal Superior del Distrito Judicial de Bogotá (2011), la estrategia paramilitar en la ciudad de Barranquilla estuvo basada en tres ejes específicos; estos fueron:

Discurso contrainsurgente, buscando legitimar su accionar en la ciudad, amenazando a académicos, activistas sociales, defensores de derechos humanos, estudiantes y miembros de sindicatos;

Limpieza social, generando una falsa sensación de seguridad y de "protección” a la ciudadanía, y

Homicidios retributivos, como parte de su estrategia de financiación y cooptación de los espacios sociales: los que no pagaban tributos o "vacunas", eran asesinados.

Sin embargo, tales ejes deben ser complementados con la información disponible sobre la infiltración de la estructura paramilitar en instituciones estatales, empresas, Fuerzas Militares, así como en alcaldías, concejos y, en general, en el ejercicio de la acción política en la ciudad. Por tal motivo, la descripción detallada de las acciones del frente JPD en la ciudad de Barranquilla y el análisis de estas se hacen necesarios en aras de arrojar luz sobre el alcance aproximado de la influencia paramilitar en la ciudad de Barranquilla y quizá, en general, para el departamento del Atlántico. En las próximas páginas, nos propondremos mostrar detalladamente - $\mathrm{y}$ en la medida en que las fuentes secundarias lo permiten - los modos y los alcances de la infiltración del FJPD en la institucionalidad barranquillera. 


\section{Infiltración}

La infiltración o cooptación paramilitar de los espacios sociales de la ciudad de Barranquilla hizo parte de la estrategia de Jorge 40 de apoderarse de la ciudad. En este sentido, podríamos afirmar que la llegada del FJPD a Barranquilla, así como la presencia de Antonio, Gonzalo y Salomón en la ciudad, hicieron parte de un plan mayor en el cual el comandante paramilitar buscaba controlar lo relativo a finanzas, fuerzas militares y de inteligencia, política, social, electoral e institucional de la ciudad. De hecho, como lo muestra información publicada en Verdad Abierta ("El computador de 'Don Antonio', 2009; "El Plan Caribe de 'Jorge 40'”, 2013), aún después de la desmovilización de las AUC en el año 2006, Jorge 40 había ideado un plan por medio del cual podían continuar delinquiendo y recibiendo ingresos en la región Caribe, sobre todo en los departamentos de Atlántico, Magdalena y Sucre.

A partir del supuesto de que el objetivo principal de las estructuras paramilitares presentes en Barranquilla era controlar el negocio del narcotráfico y percibir las rentas que de este emanan, las acciones tomadas en la ciudad pueden ser asumidas como medios a través de los cuales buscaron alcanzar tal objetivo. Así, para poder alcanzar el control del narcotráfico en la ciudad, el FJPD buscó control en lo militar, político, financiero, social e institucional. En cada uno de estos ámbitos, las estructuras paramilitares ejercieron poder sobre la población y el territorio de la ciudad de Barranquilla y en el Atlántico.

\section{Militar}

A efectos analíticos, llamaremos militar a todo lo concerniente a las fuerzas militares, de inteligencia y seguridad del Estado, así como al consiguiente control del territorio por medio de la coerción o la fuerza.

El frente JPD, de acuerdo con declaraciones de Antonio ("Don Antonio 1 parte", 2009) e información encontrada en su computador - en el cual conservaba información contable y detallada sobre asesinatos, ingresos, pagos, aliados, información de inteligencia, entre otros - tenía en su nómina de pagos al Gaula, a parte del Ejército en la ciudad, a parte de la Policía Nacional, así como a miembros del antiguo Departamento Administrativo de Seguridad (DAS), organismo de inteligencia que respondía directamente a la Presidencia de la República. Según información aparecida en Verdad Abierta ("Don Antonio' y el crimen del alcalde de Santo Tomás [Atlántico]”, 2011), Javier Insignares, paramilitar bajo el mando de Don Antonio, era el enlace entre el frente y la Sijin, el DAS y el Gaula, y asistía a reuniones como representante del mencionado jefe paramilitar —entre estas, la posible reunión en que se decidió la muerte del entonces alcalde de Santo Tomás, Nelson Mejía-. Tal vínculo puede ser demostrado con la participación de Insiganares en la devolución de un cargamento de droga por parte de la Policía Nacional a la banda de Los 40, conformada por oficiales y agentes de policía activos y retirados (“La banda que heredó el imperio de Jorge 40”, 2008).

La infiltración en estos organismos de seguridad le permitía al JFPD tener control sobre el seguimiento que la Fuerza Pública podría estar haciendo a sus actuaciones, así como el control militar extensivo de zonas en las cuales actuaban las Fuerzas Militares, la participación en operaciones conjuntas, el acceso a información exclusiva de inteligencia militar y, en este mismo sentido, manejar información de las investigaciones que estaban siendo llevadas a cabo en contra de miembros del frente. Así, existían rubros para pagos a miembros del B-2 y de las fuerzas urbanas del Ejército, así como de agentes de policía, por medio de los cuales buscaban que no persiguieran a los miembros de la estructura paramilitar, o que les informaran sobre redadas $\mathrm{u}$ operativos en su contra ("Así opera el imperio criminal de 40", 2006). En total, en sobornos a militares, policías y funcionarios, se habrían gastado unos 718 millones de pesos.

El prontuario de armamento y de tácticas militares también ayudó al frente. De acuerdo con las declaraciones de Pérez, en entrevista con Semana ("Yo le di la plata a Maloof", 2007), el Gaula les daba a los paramilitares juegos de placas para carros, entrenamientos en tácticas militares, así como salvoconductos, 
munición y camuflados - los cuales eran vendidos a estos por 60.000 pesos- Esta situación es paradójica, ya que, según estudios realizados por Urrutia, Ortega y Andrade (2009, citados en "Impactante estudio descubre de dónde venían armas de AUC”, 2009), el nivel de desvío de armas de las fuerzas de seguridad colombianas a las AUC es bajo. Esto, considerando que el porcentaje de armas de origen colombiano o de Israel (países desde los cuales proviene gran parte del armamento privativo de las Fuerzas Militares colombianas) alcanza solamente el 3,5\% y $25 \%$ del total, si se suman a este último las provenientes de Estados Unidos. Sin embargo, no puede negarse que hubo un número significativo de armas del Ejército y la Policía que fueron utilizadas por el frente JPD.

El caso paradigmático de infiltración paramilitar en organismos de inteligencia se dio en el DAS. De acuerdo con declaraciones de Rafael García, exjefe de informática del DAS ("Entrevista exclusiva con el exdirector del DAS, Rafael García, completa y sin editar. Parte 4", 2009), tanto Jorge 40 como Carlos Castaño —en ese entonces, máximos jefes de las AUC — querían que Emilio Vence fuera nombrado director del DAS de Barranquilla. Tal deseo se hizo realidad gracias a la influencia que estos tenían sobre Jorge Noguera (investigado y condenado por vínculos con grupos paramilitares), quien era ya director del DAS. El objetivo de estos jefes paramilitares al hacer nombrar a alguien cercano como director del DAS de la ciudad, era controlar la inteligencia de quiénes eran considerados narcotraficantes, quiénes no, a quién se le seguía investigando, qué líderes sociales, defensores de derechos humanos y sindicalistas había, así como sus direcciones, contacto y forma de seguimiento ${ }^{\text {xiv }}$. De hecho, como bien lo describe García en la ya mencionada entrevista ("Entrevista exclusiva con el exdirector del DAS, Rafael García, completa y sin editar. Parte 4", 2009), el nivel de cercanía del DAS con las estructuras paramilitares era tal que la Oficina de Informática del DAS, de la cual García era jefe, recibía las solicitudes de extradición reportadas por la Cancillería y las redirigía a las estructuras paramilitares, eliminando al mismo tiempo cualquier registro de inteligencia que estuviera presente en las bases de datos del DAS.

Como también lo revela García en entrevista con Semana ("Entrevista exclusiva con Rafael García”, 2006), y Antonio en entrevista con Verdad Abierta ("Don Antonio 1 parte”, 2009), fue a través de la información de inteligencia proporcionada por el DAS que se dio la orden de asesinar al profesor y sociólogo Alfredo Correa de Andréis, y, entre otros tantos, a Adán Pacheco, sindicalista de Electricaribe; Pedro Pérez, de la Defensoría del Pueblo; Orlando Londoño Palacio, veedor de transporte; Eislen Escalante Pérez, quien instauró denuncias contra la regional de la Red de Solidaridad por donaciones a ONG ficticias, y Miguel Espinosa, miembro del sindicato del DANE (“Así opera el imperio criminal de 40”, 2006).

Finalmente, la infiltración militar en organismos de seguridad estatales fue tal que en algunos casos se organizaron tropas y actos de inteligencia, concordados entre estructuras paramilitares y Fuerzas Militares, para derrocar al gobierno vecino de Venezuela, en ese tiempo presidido por Hugo Chávez Frías. Según García ("Entrevista exclusiva con el exdirector del DAS, Rafael García, completa y sin editar. Parte 4", 2009), hubo movilización de tropas paramilitares y de inteligencia del DAS a la frontera con el vecino país, de modo tal que desde esta se pudieran coordinar acciones en contra del régimen vecino.

\section{Politico}

El interés del Bloque Norte en lo político llegó tardíamente, después de su ocupación territorial y militar en gran parte de la costa Caribe. Jorge 40 estableció alianzas con políticos en diferentes instancias territoriales, como concejos, alcaldías, asambleas, gobernaciones, y aun con representantes a la Cámara y senadores. La infiltración paramilitar en el Congreso de la República fue tal que, según Salvatore Mancuso, comandante paramilitar, "el 35\% del Congreso fue elegido [en el año 2003] en zonas de influencia de las AUC" ("Mancuso: 'El 35 por ciento del Congreso fue elegido en zona de influencia de las AUC”, 2005). 
En el caso del departamento del Atlántico, a partir del escándalo de la parapolítica se investigó a diversos representantes a la Cámara, senadores, concejales y diputados, quienes pudieron estar involucrados con el frente JPD.

Hasta el momento, los congresistas del departamento del Atlántico que han sido implicados con la parapolítica y que están siendo investigados por la Corte Suprema de Justicia son Álvaro Ashton, exsenador por el Partido Liberal; David Char Navas, exsenador por el partido Cambio Radical. Otros tantos fueron investigados y las investigaciones siguen su curso, aunque con demoras. Entre estos últimos se encuentran Armando Benedetti y José David Name Cardoso, senadores del Partido de la U; Jaime Cervantes, Luis Eduardo Diazgranados y David Char, congresistas por el partido Cambio Radical; y los congresistas Mario Varón Olarte, Jorge Gerlein, Tarquino Pacheco y Alonso Acosta Osio, por el Partido Conservador ("Corte Suprema ordenó investigar a media clase política de la Costa Caribe”, 2012). De hecho, según el testimonio dado por investigados por parapolítica, en el Pacto de Caramelo varios dirigentes políticos del departamento del Atlántico suscribieron acuerdos con los grupos paramilitares, aunque no firmaron ningún documento (Arco Iris, 2012; "La cumbre de Caramelo", 2009).

Desde la misma Corte Suprema, además, se ordenó investigar a todos los concejales, diputados y alcaldes elegidos en el departamento del Atlántico durante los años en que el frente hizo presencia en el departamento, pero en particular al exalcalde de Barranquilla, Guillermo Hoenigsberg, así como su exsecretario de despacho, José Pérez.

Respecto de los alcaldes del departamento del Atlántico, según Gonzalo — quien aparecería en el año 2010 para declarar en casos de parapolítica一, los exalcaldes de Soledad Alfredo Arraut Varelo y Rosa Estela Ibáñez; el exalcalde de malambo Robin Hernández Casado, y el entonces alcalde de Campo de la Cruz, Carlos Gutiérrez, fueron también apoyados por las estructuras paramilitares del Bloque Norte ("Lo que alias 'Gonzalo' tiene que aclarar”, 2010).

Entre todos estos casos, el que más resalta es el del exsenador Dieb Maloof, quien fuera acusado y condenado por concierto para delinquir agravado, constreñimiento al elector y fraude electoral, y acusado por diversos desmovilizados paramilitares como el autor intelectual del crimen del entonces alcalde de Santo Tomás, Nelson Mejía (“'Don Antonio’ y el crimen del alcalde de Santo Tomás [Atlántico]”, 2011).

El caso Maloof es paradigmático, dado que provee elementos analíticos interesantes al revisar las relaciones entre la clase política barranquillera, el narcotráfico y las estructuras paramilitares. Tales relaciones podrían complejizar las hipótesis explicativas de la llegada de los paramilitares al departamento del Atlántico y, en particular, a la ciudad de Barranquilla.

En primer lugar, demuestra que la relación entre el narcotráfico y la política fue muy cercana. En una entrevista dada por quien fuera en algún momento miembro del frente JPD, Jaime Pérez Charris ("Yo le di la plata a Maloof", 2007), se describe la relación entre el ya mencionado exsenador y Boliche, en su momento mano derecha de Salvatore Mancuso, y quien habría sido uno de los encargados por este para exportar cocaína desde el Caribe. Las declaraciones de Pérez Charris detallan que Maloof, a través de Boliche, conocía de las actividades ilícitas de este y participaba de ellas, recibiendo además apoyo financiero y electoral por parte del mismo comandante de las AUC Carlos Castaño y de Don Antonio. Existían también acuerdos previos con Maloof, así como reuniones entre este, Gonzalo, Don Antonio, Jorge 40 y Carlos Castaño, en que definían aspectos propios del mapa electoral del Caribe ("Parapolítica: Dieb Maloof”, 2013) ${ }^{\mathrm{xv}}$.

La cercanía entre el narcotráfico y la política permitía que los primeros incursionaran en el ámbito político, ya fuera directamente - como Maloof-, o indirectamente, a través de políticos que conocían de las actividades delictivas de quienes los apoyaban, y aun así recibían apoyo de estos y los favorecían financieramente, a través de contratos, concesiones, o la simple connivencia con sus actividades delictivas en el territorio.

El testimonio de Pérez Charris da también cuenta de la intrínseca relación entre el narcotráfico y los paramilitares. Los narcotraficantes hicieron parte directa de la operación de las estructuras paramilitares en 
el departamento del Atlántico, y en este sentido se puede inferir que las acciones de estas últimas estuvieron directamente influenciadas por los intereses que tuvieran en rutas de transporte y exportación de cocaína, protección de cargamentos y manejo del tráfico de esta en el departamento ("Yo le di la plata a Maloof”, 2007).

Sobre la relación entre estructuras paramilitares y política existen testimonios múltiples en diferentes partes del Caribe colombiano. Como lo muestra información aparecida en Verdad Abierta ("El Plan Caribe de 'Jorge 40”, 2013), Jorge 40 tenía un plan para la región, cuyo objetivo era apoyar a políticos que fueran afines a la "causa paramilitar" y asegurarse de que estuvieran en cargos de elección popular.

Sin embargo, el comandante del Bloque Norte no se encargó directamente de la negociación y acercamiento con políticos de la región. Esto fue manejado, tanto en el Bloque Norte como en el frente JPD, por Gonzalo y el Canoso. Según sus declaraciones (Arrázola, 2012; Marín, 2011; "Yo le di la plata a Maloof”, 2007; "Lo que alias 'Gonzalo' tiene que aclarar”, 2010), en el departamento del Atlántico los paramilitares no tuvieron que buscar a los políticos, sino que fueron los políticos quienes buscaron a los paramilitares.

Este aspecto particular hace más intricado el panorama, dado que implicaría que los políticos del Atlántico buscaron el apoyo de organizaciones ilegales narcotraficantes para así lograr su predominancia electoral en el departamento. Las declaraciones hechas por el Canoso (Arrázola, 2012) demuestran reuniones constantes con caciques electorales del departamento, la negociación sobre cargos públicos en diferentes instituciones estatales, así como el apoyo a campañas electorales de exalcaldes de la ciudad, las cuales, apoyadas con lo dicho por Gonzalo ("La confesión de alias 'Gonzalo', 2013), revelan que la clase política atlanticense negoció directamente con las estructuras paramilitares la repartición del poder político en el Atlántico, negociando, actuando y planeando conjuntamente sus acciones en el departamento, de acuerdo con los intereses de cada uno.

Si se considera la gran cantidad de congresistas investigados, las trabas que han tenido las investigaciones - entre otras cosas, por el manejo indebido de procesos judiciales en la Corte Suprema de Justicia y en la Fiscalía (Gómez, 2017) - y cuántos de estos seguían, hasta hace algunos meses, en sus cargos (como fue el caso de Álvaro Ashton), deja muchas dudas respecto de hasta qué punto ha sido investigado el tema político en la ciudad. Futuras investigaciones deberán dar cuenta sobre los detalles de la infiltración paramilitar en la política barranquillera y sobre cómo aún hoy en día existen remanentes de tal infiltración en el poder local.

\section{Finanzas}

Financieramente, el frente JPD contaba con diversidad de ingresos que le permitían sostenerse en el tiempo, con una nómina aproximada de trescientos combatientes, además de pagos a miembros del Ejército, la Policía Nacional, el Gaula, jueces, magistrados y fiscales.

Uno de los mayores ingresos del frente provenía del narcotráfico. Según Trejos y Posada (2014), este podía representarles alrededor de dos millones de dólares por año. Esto incluía no solo exportaciones — de las cuales se encargaba directamente Salomón, quien le respondía directamente a Jorge 40 ("El computador de 'Don Antonio", 2009)—, sino el "cobro o impuesto de gramaje de los estupefacientes y sustancias ilícitas que atravesaban o se despachaban a la zona” (Tribunal Superior del Distrito Judicial de Bogotá, Sala de Justicia y Paz, 2011), refiriéndose particularmente a los municipios de Puerto Colombia, Juan de Acosta, Tubará y Piojó, pero también a través del puerto principal y puertos privados de Barranquilla. Sobre esto, en la contabilidad almacenada en el computador de Don Antonio, se encontró que se sacaba droga a través de contenedores llenos de banano, con la connivencia de las fuerzas de seguridad estatales, hasta el punto de crear una banda conformada por agentes activos y retirados, a través de la cual exportaban cocaína por el puerto de Barranquilla (“Así opera el imperio criminal de 40”, 2006; “'Don Antonio' y el crimen del alcalde de Santo Tomás [Atlántico]”, 2011).

Otra fuente importante de financiación fue el Estado. Como indican Trejos y Posada (2014), citando a Garay (2010), en la ciudad de Barranquilla se dio una reconfiguración cooptada del Estado, por medio de la 
cual obtuvieron rentas y saquearon el erario. Tal situación se extendió alrededor de todo el departamento del Atlántico, de múltiples formas.

En el caso de la ciudad de Barranquilla, según grabaciones de la Fiscalía General de la Nación, el FJPD obtuvo rentas de dineros desviados de la licitación de manejo de aguas, alcantarillado y aseo de la ciudad, en cabeza de la empresa Triple A, equivalentes al 10\% de los dineros destinados a la adecuación de caños del municipio. También, es posible que hayan recibido una comisión por adelantado de la construcción de Transmetro ("Así opera el imperio criminal de 40", 2006). A su vez, el frente tuvo relaciones cercanas con la firma Métodos y Sistemas, en ese momento dirigida por Eduardo Losada ${ }^{\text {xvi }}$, la cual se encargaba de la recolección de impuestos en la ciudad. A través de esta, según el testimonio de varios exparamilitares (Arrázola, 2012; "Lo que alias 'Gonzalo' tiene que aclarar”, 2010) y lo encontrado en el computador de Don Antonio ("Así opera el imperio criminal de 40”, 2006), se dio dinero a la campaña del entonces candidato a la alcaldía y ganador de la contienda electoral Guillermo Hoenigsberg, a cambio de la participación de la estructura paramilitar en las finanzas del Distrito ("Corte Suprema ordenó investigar a media clase política de la Costa Caribe", 2012).

Otro esquema utilizado en la ciudad para las finanzas fue la cooptación de recursos de la salud a través de las EPS Solsalud y Salud Total, encabezadas por Dieb Maloof, en sociedad con el comerciante Dino Gravini Donado y Ernesto Barceló ("Las nuevas revelaciones de Rafael García, ex jefe de informática del DAS, sobre la 'parapolítica"', 2006).

Ahora bien, dado que las operaciones del frente se extendían a todo el departamento, vale la pena mirar sus acciones para apoderarse de las finanzas en todo el Atlántico. En los años en que hizo presencia en el departamento, de acuerdo con información dada a conocer por El Tiempo ("Así opera el imperio criminal de 40", 2006), se realizaron las siguientes acciones:

Creación de una empresa falsa para desviar 1.500 millones de pesos de la Alcaldía de Sabanagrande. Cooptación del Hospital Materno Infantil de Soledad, siendo manejadas las finanzas de este por personas cercanas a 'Don Antonio', entre otros, su esposa, su hermana y un cuñado (Romero y Ávila, 2011).

Durante el proceso de paz entre las AUC y el Gobierno Nacional, se desviaron 30 millones de pesos de una IPS en el municipio de Soledad.

Participaron en contratos por compra de tubería en Galapa, así como de obras públicas en Palmar de Varela y Malambo.

Según el balance hecho por Don Antonio en su computador, en siete meses de robo al Estado en el año 2004, el frente obtuvo unos 3200 millones de pesos.

Otros ingresos provenían del robo de gasolina, el cual llegó a significar ingresos por unos 1370 millones de pesos, además de extorsiones y vacunas a pequeños y medianos comerciantes, avaluadas en unos 500 millones de pesos.

En total, y para dar una idea de la magnitud de los recursos que el frente manejaba, en el 2005 - ya iniciada la negociación con el Gobierno-, los ingresos habrían sido de unos 3000 millones de pesos.

Con estos recursos, manejados casi en su totalidad por Don Antonio, los paramilitares lograron mantener parte de su estatus en la ciudad. Así, por ejemplo, como lo describe información aparecida en El Tiempo ("Así opera el imperio criminal de 40", 2006), en pagos y sobornos a funcionarios, militares y policías, se habrían gastado unos 718 millones de pesos; otros 32 millones de pesos en un rubro denominado "Ley", que podría haber sido para miembros de la Fuerza Pública de Barranquilla, de modo tal que no hicieran operaciones en contra del frente; otro presupuesto, llamado "arreglo situación jurídica", destinado al parecer a pagar sobornos a empleados de la rama judicial; unos dos millones de pesos, denominados "pago de información de Fiscalía”; además de la destinación de tres millones de pesos a dos capitanes de las fuerzas urbanas del Ejército, así como posibles cuentas y rubros destinados a agentes del entonces B-2 quienes le informaban a cualquier hora del día para prevenir capturas de integrantes de las AUC.

Todo esto da una idea del poder económico que tenía el frente JPD, y que, sin lugar a duda, le permitió estar en la ciudad aún después de haber comenzado el proceso de desmovilización. 


\section{Social e institucional}

El FJPD generó terror en la ciudad de Barranquilla. A través de asesinatos selectivos, logró implantar un orden social coherente con los objetivos de la estructura paramilitar. Como lo muestra información publicada en Verdad Abierta ("El paso macabro de las AUC por Atlántico", 2011), el paso de este frente por la ciudad dejó una estela de asesinatos y desapariciones. Solo entre el 2004 y el 2006, el FJPD cometió 1664 homicidios; el desplazamiento forzado pasó de 966 personas en 1999, a 6297 en el 2000, y a 10.778 en el 2001. Todas estas cifras dan una imagen cuantitativa de lo sucedido, pero las acciones en el ámbito de lo social dejaron marcas profundas en la sociedad barranquillera.

Una de estas marcas fue la tolerancia que la sociedad tuvo con las acciones del frente. Como lo explican Trejos y Posada (2014), la población comenzó a aceptar las acciones del grupo ilegal, justificadas en expresiones como "limpieza social", en las cuales se asesinaba a prostitutas, jíbaros y drogadictos. Bajo esta misma figura, estudiantes, sindicalistas, líderes sociales y defensores de derechos humanos fueron catalogados como objetivo militar, y si bien realizaban las respectivas denuncias, la población justificaba tales asesinatos como necesarios para el orden social.

En el caso de la ciudad de Barranquilla, como lo describe el Canoso (Arrázola, 2012), la clase dirigente se reunió constantemente con miembros de las AUC, acción que justifica y reconoce al grupo paramilitar como actor político y militar en la ciudad.

Del mismo modo, como expresa García ("Entrevista exclusiva con el exdirector del DAS, Rafael García, completa y sin editar. Parte 4”, 2009), la institucionalidad se movió y reconfiguró a favor de los paramilitares, del modo en que Garay (2010) denominó reconfiguración cooptada del Estado. En la ciudad, miembros de la Alcaldía de Barranquilla, empresas públicas, empresas privadas (como Métodos y Sistemas), miembros de la Fuerza Pública, y aun jueces, magistrados y fiscales, fueron cooptados por el paramilitarismo, irrumpiendo en el escenario social y modificándolo a su modo. Así, los paramilitares no entran y se ajustan a la población, su nivel socioeconómico y los niveles de conflicto, como lo afirman Velásquez y Zuluaga Nieto (2009), sino que irrumpen en escenarios sociales, los modifican y generan dinámicas de conflicto armado, como lo demuestra el caso de la ciudad de Barranquilla.

\section{Conclusiones}

En la ciudad de Barranquilla han hecho presencia activa distintos actores armados, pero en el periodo analizado lo hicieron activamente por medio del Frente Urbano Kaleb Gómez Padrón del Ejército de Liberación Nacional (ELN), la Red Urbana José Antequera (RUJA) de las Fuerzas Armadas Revolucionarias de Colombia - Ejército del Pueblo y el Frente José Pablo Díaz de las Autodefensas Unidas de Colombia (AUC), que al igual que organizaciones de narcotraficantes que llegaron a la ciudad por su dinamismo económico y comercial (fundamental para la captura de rentas y acceso a bienes y servicios), y también por su privilegiada condición de puerto marítimo y desembocadura del río Magdalena. Precisamente, esta ubicación geográfica ha hecho de Barranquilla un punto estratégico para la exportación de clorhidrato de cocaína y el ingreso de dólares, armas e insumos químicos.

Para las organizaciones guerrilleras, la ciudad resultaba estratégica por varios motivos, entre ellos, el que la cuidad y el departamento del Atlántico funcionan como bisagras entre dos sistemas montañosos que albergaron el grueso de las estructuras guerrilleras rurales que operaron en la región Caribe, la Sierra Nevada de Santa Marta (Cesar, Guajira y Magdalena) y los Montes de María (Bolívar y Sucre); además, su dinamismo comercial la convierte en una fuente de acceso a bienes y servicios; y también por la gran cantidad de organizaciones sociales (influenciables y cooptables) presentes en su territorio. 
Para las estructuras paramilitares, Barranquilla representó un punto de empalme entre sus acciones en el norte y sur de la costa norte colombiana. La ciudad representó una fuente de ingresos, acceso a servicios e influencia en la institucionalidad formal e informal, desde lo militar, pasando por lo político, y llegando a lo social. Se puede afirmar que en la ciudad de Barranquilla existe una conexión entre el narcotráfico, el paramilitarismo y la clase política, en la cual los dos primeros negocian con los segundos, y viceversa. En ese sentido, la infiltración y negociación entre estas estructuras y la clase política puede ser considerada la negociación entre narcotraficantes y políticos, los cuales alcanzaron sus propios objetivos a través de la colaboración y el establecimiento de objetivos comunes.

\section{Referencias}

Arco Iris. (2012). El de Chivolo no fue el único pacto entre las AUC y los políticos. Fundación Nuevo Arco Iris. Recuperado de https://www.arcoiris.com.co/2012/05/el-de-chivolo-no-fue-el-unico-pacto-entre-las-auc-y-lospoliticos/

Ardila, E., Acevedo, Á. y Martínez, L. (2012). Memorias de violencia: bonanza marimbera en la ciudad de Santa Marta durante la década del setenta al ochenta. Santa Marta: Editorial Unimagdalena

Arias, A. (2008). Contexto de violencia y conflicto armado. En C. López (coord. y ed.), Monografía politico-electoral del departamento del Atlántico 1997 a 2007 (pp. 2-25). Bogotá: Misión de Observación Electoral, Corporación Nuevo Arcoíris, Universidad de los Andes.

Arrázola, M. (2012). La confesión de 'El Canoso'. El Espectador. Recuperado de https://www.elespectador.com/noti cias/judicial/confesion-de-el-canoso-articulo-338337

Asesinan al recaudador de impuestos de Barranquilla. (2004, 22 de junio). caracol.com. Recuperado de http://caracol .com.co/radio/2004/06/22/judicial/1087855200_087113.html

Así fue cómo los paramilitares se tomaron el departamento del Atlántico. (2007, 3 de febrero). eltiempo.com. Recuperado de http://www.eltiempo.com/archivo/documento/CMS-3425301

Así opera el imperio criminal de 40. (2006, 8 de octubre). eltiempo.com. Recuperado de http://www.eltiempo.com/a rchivo/documento/MAM-2231628

Audiencia concentrada del "Frente Pivijay”. (2015, 22 de abril). El Heraldo. Recuperado de https://www.elheraldo.c o/judicial/audiencia-concentrada-del-frente-pivijay-192342

Auge y caída de las dinastías del narcotráfico en México. (2014, 22 de febrero). BBC. Recuperado de http://www.bbc .com/mundo/noticias/2013/09/130903_mexico_auge_caida_dinastias_cartel_drogas_carrillo_fuentes_jcps

Bonilla, L. (2010). El sector industrial de Barranquilla en el siglo XXI: ¿Cambian finalmente las tendencias? Cartagena de Indias: Centro de Estudios Regionales del Banco de la República.

Brito, S. (2008). Contrabandistas, marimberos y parranderos: región y nación durante la bonanza de la maribuana en la Guajira, Colombia, 1970 (tesis de maestría). Universidad de la Cordillera, La Paz, Bolivia.

Cámara de Comercio de Barranquilla. (2016). Boletín de coyuntura económica del Atlántico. Barranquilla: autor.

Celos enfermizos del "Mellizo". (2014, 1.o de febrero). semana.com. Recuperado de http://www.semana.com/nacion /articulo/celos-enfermizos-del-mellizo/375794-3

Corte Suprema ordenó investigar a media clase política de la Costa Caribe. (2012, 6 de septiembre).verdadabierta.com. Recuperado de https://verdadabierta.com/corte-suprema-ordena-investigar-a-media-clase-politica-de-la-costacaribe/

Cupo del “Mellizo" en proceso con las AUC valió US\$ 2 millones. (2017, 16 de septiembre). eltiempo.com. Recuperado de http://www.eltiempo.com/justicia/conflicto-y-narcotrafico/detalles-de-como-entro-narco-mellizo-en-proc eso-con-las-auc-131476

Desmantelan un cartel del narcotráfico. (1998). lanacion.com. Recuperado de https://www.lanacion.com.ar/99324-d esmantelan-un-cartel-del-narcotrafico 
Don Antonio 1 parte. (2009, 14 de agosto). verdadabierta.com. Recuperado de https://www.youtube.com/watch?v $=\mathrm{Qq} 65 \mathrm{I} 82 \mathrm{kSDU}$

Don Antonio, el hombre detrás del computador de Jorge 40. (2009, 14 de agosto). verdadabierta.com. Recuperado de https://verdadabierta.com/don-antonio-el-hombre-computador/

"Don Antonio" y el crimen del alcalde de Santo Tomás (Atlántico). (2011, 13 de octubre). verdadabierta.com. Recuperado de https://verdadabierta.com/ex-senador-dieb-maloof-senalado-por-asesinato-de-alcalde-de-santo -tomas/

Efecto dominó. (1999, 26 de abril). semana.com. Recuperado de http://www.semana.com/nacion/articulo/efecto-d omino/39175-3

El computador de "Don Antonio" (2009, 31 de julio). verdadabierta.com. Recuperado de https://verdadabierta.com /el-computador-de-don-antonio/

"El Chapo" Guzmán, el narco más poderoso y buscado del mundo. (2015). lanacion.com. Recuperado de https://ww w.lanacion.com.ar/1809804-quien-es-el-chapo-guzman-el-narco-mas-poderoso-del-mundo

El fin del hombre del Marlboro. (2002, 13 de octubre). eltiempo.com. Recuperado de https://bit.ly/2v1bcFg

El paso macabro de las AUC por Atlántico. (2011, 18 de octubre). verdadabierta.com. Recuperado de https://verdad abierta.com/el-paso-macabro-del-bloque-norte-por-el-atlantico/

El Plan Caribe de “Jorge 40". (2013, 30 de enero).verdadabierta.com. Recuperado de https://verdadabierta.com/el-p lan-caribe-de-jorge-40/

El silencio, sombra protectora de los "paras" en Barranquilla. (2007, 4 de febrero). eltiempo.com. Recuperado de http: //www.eltiempo.com/archivo/documento/MAM-2377829

ELN liberó a secuestrado de la ciénaga El Torno. (25 de agosto del 2000). eltiempo.com. Recuperado de http://www. eltiempo.com/archivo/documento/MAM-1290223.

Entrevista exclusiva con el exdirector del DAS, Rafael García, completa y sin editar. Parte 4. (2009). Noticias Uno. Recuperado de https://www.youtube.com/watch?v=Y4Su5LdXUu8

Entrevista exclusiva con Rafael García. (2006, 4 de agosto). semana.com. Recuperado de http://www.semana.com/po rtada/articulo/entrevista-exclusiva-rafael-garcia-completa/78261-3

Exonerado Emilio Vence del proceso que le seguía la Fiscalía. (2010, 27 de junio). El Pilón. Recuperado de http://elp ilon.com.co/exonerado-emilio-vence-del-proceso-que-le-seguia-la-fiscalia/

Extinción de dominio arrancó en Barranquilla. (1997, 22 de marzo). eltiempo.com. Recuperado de http://www.eltiem po.com/archivo/documento/MAM-536510

Garay, L. J. (2010). Crimen, captura y reconfiguración cooptada del Estado: Cuando la descentralización no contribuye a profundizar la democracia. En 25 años de la descentralización en Colombia (pp. 89-138). Bogotá: Konrad Adenauer Stiftung.

Golpe al Cartel de la Costa en el Atlántico. (1993, 29 de diciembre). eltiempo.com. Recuperado de http://www.eltie mpo.com/archivo/documento/MAM-281692

Gómez, C. (2017, 1. ${ }^{\circ}$ de octubre). Seis lecturas para entender el cartel de la toga. El Espectador. Recuperado de https: //www.elespectador.com/noticias/judicial/seis-lecturas-para-entender-el-cartel-de-la-toga-articulo-715926

González-Plazas, S. (2008). Pasado y presente del contrabando en La Guajira aproximaciones al fenómeno de ilegalidad en la región. Bogotá: Editorial Universidad del Rosario, Documentos de Investigación.

Harnecker, M. (1988). Colombia: Combinación de todas las formas de lucha. Bogotá: Ediciones Suramericanas.

Impactante estudio descubre de dónde venían armas de AUC. (2009, 27 de noviembre). semana.com. Recuperado de http://www.semana.com/nacion/conflicto-armado/articulo/impactante-estudio-descubre-donde-venian-a rmas-auc/110312-3

La banda que heredó el imperio de Jorge 40. (2008, 21 de octubre). verdadabierta.com. Recuperado de https://verda dabierta.com/la-banda-que-heredo-el-imperio-de-jorge-40/ 
La barbarie (1. ${ }^{\circ}$ de agosto del 2001). semana.com. Recuperado de http://www.semana.com/nacion/articulo/la-barb arie/44678-3

La confesión de alias "Gonzalo". (2013, 3 de noviembre). El Espectador. Recuperado de https://www.elespectador.co $\mathrm{m} /$ noticias/nacional/confesion-de-alias-gonzalo-articulo-456408

La cumbre de Caramelo. (2009, 24 de abril). semana.com. Recuperado de https://www.semana.com/on-line/articulo /la-cumbre-caramelo/92308-3

La historia de Jaime Pérez, el falso testigo asesinado. (2013, 24 de noviembre). El Heraldo. Recuperado de https://ww w.elheraldo.co/judicial/la-historia-de-jaime-perez-el-falso-testigo-asesinado-133425

La masacre de Nueva Venecia se originó en Pivijay. (2008, 17 de diciembre). verdadabierta.com. Recuperado de https: //verdadabierta.com/la-masacre-de-nueva-venecia-se-origino-en-pivijay/

Las nuevas revelaciones de Rafael García, ex jefe de informática del DAS, sobre la "parapolítica". (2006, 28 de diciembre).eltiempo.com. Recuperado de http://www.eltiempo.com/archivo/documento/CMS-3381919

Lenin, V. (1980) ¿Qué hacer? En Obras escogidas (pp. 3-78). Moscú: Editorial Progreso.

Lo que alias "Gonzalo" tiene que aclarar. (2010, 13 de noviembre). verdadabierta.com. Recuperado de https://verdad abierta.com/lo-que-alias-gonzalo-no-ha-dicho/

López, C. N. y Ávila, A. F. (eds.). (2010). Y refundaron la patria: De cómo mafiosos y políticos reconfiguraron el Estado colombiano. Bogotá: Debate.

"Los mellizos", Miguel Ángel Mejía Múnera y Víctor Manuel Mejía Múnera. (2008, 29 de diciembre). verdadabierta.com. Recuperado de https://verdadabierta.com/perfil-de-miguel-angel-mejia-munera-y-victor-m anuel-mejia-munera-alias-los-mellizos/

Los narcogemelos. (2001, 10 de enero). semana.com. Recuperado de http://www.semana.com/nacion/articulo/los-n arcogemelos/47421-3

Mancuso: "El 35 por ciento del Congreso fue elegido en zona de influencia de las AUC”. (2005, 4 de agosto). Caracol Radio. Recuperado de http://caracol.com.co/radio/2005/08/04/judicial/1123166760_191922.html

Marín, A. (2011, 7 de agosto). Alias 'El Canoso', cerebro tayrona. El Espectador. Recuperado de https://www.elespect ador.com/noticias/judicial/alias-el-canoso-cerebro-tayrona-articulo-290092

Meisel, A. (1993). Por qué se disipó el dinamismo industrial de Barranquilla. En A. Meisel y E. Posada-Carbó, Por quése disipó el dinamismo industrial de Barranquilla y otros ensayos de historia económica de la Costa Caribe (pp. 9-41). Barranquilla: Ediciones Gobernación del Atlántico.

Montes, A., Marti\#nez, L., Marti\#nez, N., Rena\#n, W.y Silva, F. (2014). Memorias y narrativas: Tres décadas de conflicto armado en el Magdalena Grande. Bogotá: Editorial de la Universidad del Magdalena.

Observatorio del Programa Presidencial de Derechos Humanos y DIH. (2005). Dinámica reciente de la violencia en Barranquilla. Bogotá: autor.

Observatorio del Programa Presidencial de Derechos Humanos y DIH. (2012). Diagnóstico de la situación de derechos humanosy DIH del departamento del Atlántico 2000 - Isemestre de 2011. Bogotá: Vicepresidencia de la República de Colombia.

Parapolítica: Dieb Maloof. (2013, 20 de agosto). verdadabierta.com. Recuperado de https://verdadabierta.com/para politica-dieb-maloof/

Pardinas, F. (1989). Metodología y técnicas de investigación en ciencias sociales. México: Siglo Veintiuno Editores.

Pedraza, H. y Olaya, Á. (2011). Regalías, cooperativas y finanzas paramilitares en la costa Caribe. En M. Romero (ed.), La economía de los paramilitares. Redes de corrupción, negocios y política (pp. 161-269). Bogotá: Editorial Debate.

Pérez, G. (2014). Barranquilla: avances recientes en sus indicadores socioeconómicos y logros en la accesibilidad geográfica a la red pública hospitalaria. En G. Pérez, M. Aguilera, L. Galvis, A. Otero, A. Sánchez-Jabba y K. Acosta, Economia de las grandes ciudades en Colombia: seis estudios de caso (pp. 1-43). Bogotá: Banco de la República.

Perfil de Miguel Ángel Mejía Múnera. (2008). caracol.com. Recuperado de http://caracol.com.co/radio/2008/05/02 /judicial/1209703560_588979.html 
Ragin, C. (2007). La construcción de la investigación social. Bogotá: Siglo del Hombre Editores y Universidad de los Andes.

Robert, A. y Rodier, A. (2013). Le crime organicé: du Canada à la Terre de Feu. Mónaco: Editions du Rocher.

Rodríguez, J. (2016). Barranquilla siempre tendrá Miss Universo. Recuperado a partir de https://www.elheraldo.co/ local/barranquilla-siempre-tendra-miss-universo-247158

Romero, M.y Ávila, A. F. (eds.).(2011).La economía de losparamilitares: Redes decorrupción, negociosypolítica. Bogotá: Debate.

Salinas, Y. y Zarama, J. M. (2012). Justicia y Paz: tierras y territorios en las versiones de los paramilitares. Bogotá: Centro Nacional de Memoria Histórica.

Se entregó el ex director del DAS en el Atlántico, Emilio Vence. (15 de noviembre del 2005). Recuperado de http://c aracol.com.co/radio/2005/11/15/judicial/1132089900_221331.html

Toma del ELN en las Malvinas. (30 de mayo de 1988). Diario del Caribe, Judiciales, p. 2.

Trejos, L. (2013). Aproximación a las dinámicas del crimen organizado en la ciudad de Barranquilla. El caso del Frente José Pablo Díaz de las Autodefensas Unidas de Colombia (2000-2006). Revista Justicia, 24, 118-134. doi: http s://doi.org/10.17081/just.18.24.680

Trejos, L. (2017). Narcotráfico en la región Caribe. Bogotá: Observatorio Colombiano de Violencia y Gobernanza \& Friedrich Ebert Stiftung.

Trejos, L. y Posada, A. (2014). Paramilitarismo en la ciudad de Barranquilla. Crimen organizado y mercados de violencia. Revista de Economia del Caribe, O(14). https://doi.org/10.14482/rec.v0i14.7064

Tribunal Superior del Distrito Judicial De Bogotá, Sala de Justicia y Paz (2011). Sentencia de Primera Instancia contra implicados Édgar Ignacio Fierro Flores y Andrés Mauricio Torres León. Radicado 110016000253-200681366. M. P. Léster González Romero.

Urrutia, N., Ortega, M. y Andrade, G. (2009). Rastreo de armas: perspectivas sobre el control, tráfico y uso de armas ilegales en Colombia. Bogotá: Fundación Ideas para la Paz.

Valencia, L. (2009). Municipio y violencia paramilitar en Colombia 1984-2008. En F. Velásquez, J.Zuluaga, L. Valencia, F. Cubides, E. González, C. Rodríguez et al., Las otras caras del poder: Territorio, conflicto y gestión pública en municipios colombianos (pp. 141-181). Bogotá: GTZ, Foro Nacional por Colombia.

Velásquez C., F. y Zuluaga Nieto, J. (eds.). (2009). Las otras caras del poder: Territorio, conflicto y gestión pública en municipios colombianos. Bogotá: GTZ, Foro Nacional por Colombia.

Villalón, J. (2003). Crisis urbana y conflictos políticos a mediados de los años ochenta en Barranquilla. En L. Sánchez, P. Ospino, J. Parada, M. Buelvas, J. Núñez y J. Villalón, Barranquilla: lecturas urbanas (pp. 115-136). Barranquilla: Observatorio del Caribe Colombiano y Universidad del Atlántico.

Villarraga, Á. y Plazas, N. (1994). Para reconstruir los sueños. Bogotá: Fundación Editorial para la Paz, Fundación Cultura Democrática y Colcultura.

Yo le di la plata a Maloof. (2007, 17 de febrero). semana.com. Recuperado de http://www.semana.com/nacion/artic ulo/yo-di-plata-maloof/83535-3

Yo le hice "lobby" a la Ley de justicia y paz. (2006, 14 de octubre). semana.com. Recuperado de https://www.semana .com/nacion/articulo/yo-hice-lobby-ley-justicia-paz/81451-3

\section{Notas}

i Para la realización de este trabajo fue imposible conseguir una entrevista con algún exmiembro de la Red Urbana José Antequera de las FARC-EP.

ii El Atlántico es el segundo departamento más pequeño de Colombia, solo es más grande que Quindío, y en términos de capitales departamentales, Barranquilla solo es más grande que Bucaramanga, Manizales y Tunja.

iii "En Barranquilla, por ejemplo, en un colegio, donde todos los alumnos, los profesores y el rector eran simpatizantes o militantes del Partido, todos los días hacían formar a los muchachos y en la izada de bandera cantaban 'El Turbión': 'Soy 
soldado de aquellos valientes/ que enterraron el yugo español/ de Galán tengo el odio a los amos/ y el coraje de Vásquez Rendón”" (Villarraga y Plazas, 1994, p. 70).

iv La entrevista se realizó en la ciudad de Santa Marta en el mes de enero del 2018. El entrevistado dejó el ELN en el 2004, año en que se reintegró a la vida civil por medio de los programas gubernamentales. En la actualidad se dedica al ejercicio de su profesión y la construcción de paz.

v En entrevista con Harnecker (1988), la dirigencia del ELN manifestaba que: "Un frente guerrillero, el concepto se extiende más allá del núcleo armado. El frente guerrillero tiene además de guerrillas, organización política de base y un área geográfica determinada de actividades político-organizativas y militares. Durante varios meses, muchos guerrilleros [...] se dedican a organizar a la población. Un frente guerrillero nuestro es un grupo de hombres en armas, pero también una serie de grupos [...], de colectivos de militantes y premilitantes, donde hay milicias, donde hay diversos núcleos de trabajo de la organización en una zona dada” (p. 57).

vi En el cual se pregunta: ¿Cómo conciliar esta contradicción entre la necesidad de una organización amplia y de una clandestinidad rigurosa? ¿Cómo conseguir que las organizaciones gremiales sean lo menos clandestinas posible? En general, no puede haber más que dos caminos: o bien la legalización de las asociaciones gremiales (que en algunos países ha precedido a la legalización de las organizaciones socialistas y políticas), o bien el mantenimiento de la organización secreta, pero tan 'libre', tan poco reglamentaria, que la clandestinidad quede reducida casi a cero para la masa de afiliados" (Lenin, 1980, p. 76).

vii En Cartagena también operó el Frente Urbano Héroes de Cartagena.

viii Esta fue una operación que tuvo por objetivo desmantelar una banda de narcotráfico que transportaba cocaína y heroína hacia los Estados Unidos y que se presumía había utilizado la estructura proveniente del contrabando para sus fines ("El fin del hombre del Marlboro", 2002).

ix Amado Carrillo, más conocido como el Señor de los Cielos, en alusión a una gran flotilla de aviones que le pertenecía y a través de la cual enviaba la droga a los Estados Unidos, fue un famoso narcotraficante mexicano que se convirtió en el líder del Cartel de Juárez luego de asesinar a su antiguo líder, Rafael Aguilar Guajardo. Su poderío se expandió con la desarticulación de los dos grandes carteles colombianos: el de Medellín y el de Cali, y acabó con su muerte prematura en 1997 (“Auge y caída de las dinastías del narcotráfico en México”, 2014). Joaquín Guzmán Loera, mejor conocido como el Chapo Guzmán, fue el líder del Cartel de Sinaloa y, en su momento, el hombre más buscado por el FBI y la Interpol, dado que se consideraba el principal narcotraficante del mundo. Admitió haber asesinado entre 2000 y 3000 personas, y luego de fugarse varias veces en cárceles mexicanas y guatemaltecas, fue extraditado a los Estados Unidos en el 2017 (“'El Chapo' Guzmán, el narco más poderoso y buscado del mundo", 2015).

x La Operación Transatlántico fue una articulación de la policía antinarcóticos de cinco países que permitió rastrear y decomisar veinte toneladas de droga en Estados Unidos y Europa provenientes del clan de los Mejía Múnera. La Operación Orinoco permitió el decomiso de diez toneladas de coca y la captura de quince colaboradores del clan, entre ellos el tercero al mando, Iván de la Vega. Por último, la operación Horizonte Fase 2 consistía en ubicar y capturar a Félix Antonio Chitiva Carrasquilla, alias la Mica, ya que dada su cercanía con los hermanos Mejía Múnera, este podía ser el enlace para su captura ("Los narcogemelos", 2001). No obstante, el plan fracasó y la captura de la Mica produjo la desaparición de la escena de los Mejía Múnera, quienes aprovecharon este tiempo para repensar su estrategia y trasladar su centro de operaciones hacia Arauca (Observatorio del Programa Presidencial de Derechos Humanos y DIH, 2012).

xi En 1997 estas se aliaron con otras estructuras de autodefensas y lograron cooptarlas para transformarse en las Autodefensas Unidas de Colombia (AUC).

xii Cabe aclarar que el frente JPD fue rebautizado en el 2003, como consecuencia de la muerte del primer comandante del frente. Por eso, entre el 2000 y el 2003 este fue conocido como Grupo Atlántico (Trejos, 2013).

xiii A mediados de 1999, Dino Meza recibió una invitación por parte de el Pollo, un líder paramilitar, para que se uniera a las filas de las AUC. La cita para concretar el ingreso era en la finca Los Techos Rojos, en Sitio Nuevo, Magdalena. Ese día, él y otras quince personas fueron asesinados y descuartizados, y se marcó el predominio del Grupo Atlántico en el departamento ("Así fue cómo los paramilitares se tomaron el departamento del Atlántico", 2007).

xiv Curiosamente, tal situación se saldría del control de las AUC. Según García, en entrevista a Noticias Uno ("Entrevista exclusiva con el exdirector del DAS, Rafael García, completa y sin editar. Parte 4”, 2009), Vence en algunos casos no fue del agrado de los comandantes paramilitares. Fue así como, en el 2005, este fue retirado del DAS al ser investigado por diversos delitos ("Se entregó el ex director del DAS en el Atlántico, Emilio Vence”, 2005), aunque sería absuelto de todos ellos unos años después (“Exonerado Emilio Vence del proceso que le seguía la Fiscalía”, 2010).

xv El entrevistado, Jaime Alberto Pérez Charris, fue asesinado el 15 de noviembre del 2013, unos días antes de rendir su testimonio ante la Fiscalía General de la Nación (“La historia de Jaime Pérez, el falso testigo asesinado", 2013).

xvi Eduardo Losada sería asesinado el 22 de junio del 2004, en la puerta de su casa ("Asesinan al recaudador de impuestos de Barranquilla”, 2004).

* Artículo de reflexión. 


\section{Licencia Creative Commons CC BY 4.0}

Cómo citar: Martínez Martínez, F., Trejos Rosero, L. F., y Badillo Sarmiento, R. (2018). Aproximación a las dinámicas del conflicto armado en la ciudad de Barranquilla: entre la marginalidad insurgente y el control paramilitar 1990-2006". Papel Político, 23(2). 1-22. https://doi.org/10.11144/Javeriana.papo23-2.adca 